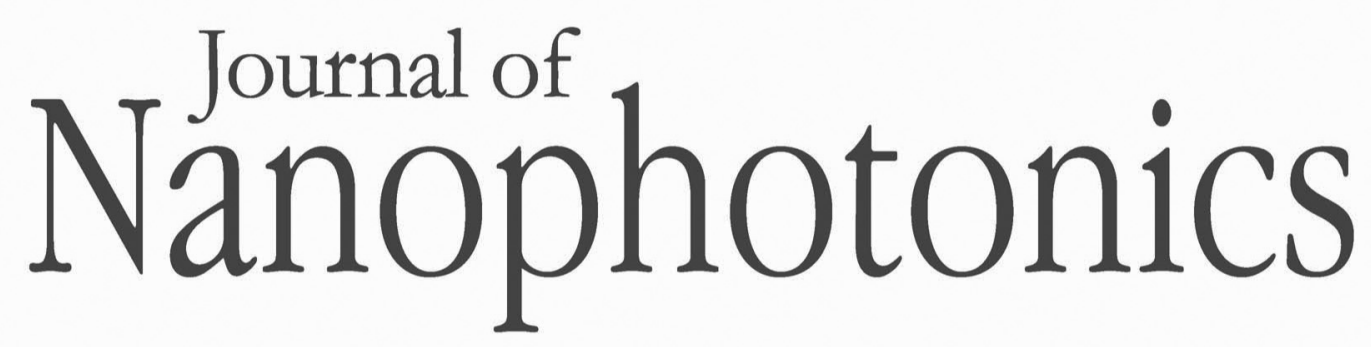

SPIEDigitalLibrary.org/jnp

\title{
Publisher's Note: Microspot sensing based on surface-enhanced fluorescence from nanosculptured thin films
}
Alina Karabchevsky
Chinmay Khare
Bernd Rauschenbach
Ibrahim Abdulhalim 


\title{
Publisher's Note: Microspot sensing based on surface-enhanced fluorescence from nanosculptured thin films
}

\author{
Alina Karabchevsky, ${ }^{\mathrm{a}}$ Chinmay Khare, ${ }^{\mathrm{b}}$ Bernd Rauschenbach, ${ }^{\mathrm{b}}$ and \\ Ibrahim Abdulhalim ${ }^{\mathrm{a}}$ \\ ${ }^{a}$ Ben-Gurion University of the Negev, Department of Electrooptic Engineering and Ilse Katz, \\ Institute for NanoScale Science and Technology, Beer-Sheva 84105, Israel \\ ${ }^{b}$ Leibniz-Institut für Oberflächenmodifizierung e.V., Permoserstrasse 15, 04318 Leipzig, \\ Germany \\ rudenko@bgu.ac.il
}

This article was originally published in Vol. 6 of the Journal of Nanophotonics on 21 June 2012 with an incorrect citation identifier (CID) of 011508. The paper was removed and republished online with the correct CID of 061508 on 25 June 2012.

For more information on the use of CIDs in JNP, see http://spiedigitallibrary.org/jnp/ citation_format.

0091-3286/2012/\$25.00 @ 2012 SPIE 